Cipango $\begin{aligned} & \text { Cipango } \\ & \text { Cahiers d'études japonaises }\end{aligned}$

18 | 2011

Le Japon et le fait colonial I

\title{
Homosexualités féminines et mariages dans le Japon des années 1980 à nos jours
}

Aline Henninger

CpenEdition

Journals

Édition électronique

URL : https://journals.openedition.org/cipango/1624

DOI : $10.4000 /$ cipango. 1624

ISSN : 2260-7706

Éditeur

INALCO

Édition imprimée

Date de publication : 1 juin 2011

Pagination : 294-297

ISBN : 978-2-85831-195-8

ISSN : $1164-5857$

Référence électronique

Aline Henninger, " Homosexualités féminines et mariages dans le Japon des années 1980 à nos

jours », Cipango [En ligne], 18 | 2011, mis en ligne le 23 septembre 2013, consulté le 30 juin 2021. URL: http://journals.openedition.org/cipango/1624 ; DOI : https://doi.org/10.4000/cipango.1624

Ce document a été généré automatiquement le 30 juin 2021.

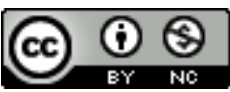

Cipango est mis à disposition selon les termes de la Licence Creative Commons Attribution - Pas d'Utilisation Commerciale 4.0 International. 


\title{
Homosexualités féminines et mariages dans le Japon des années 1980 à nos jours
}

\author{
Aline Henninger
}

\section{RÉFÉRENCE}

Aline HENNINGER, Homosexualités féminines et mariages dans le Japon des années 1980 à nos jours, mémoire de Master 2, sous la direction de Christian Galan, INALCO, 2012.

1 Le mariage au Japon n'a jamais été autant mis en valeur que depuis les années 1980, alors même que la structure maritale et familiale n'a cessé d'évoluer. À travers la question de l'homosexualité, il est possible d'interroger le statut de cette norme fondamentale dans la société japonaise, qui affiche un taux de nuptialité extrêmement élevé, et où cohabitation et concubinage demeurent extrêmement marginaux. Si la place des homosexuels masculins face à l'institution maritale a été souvent analysée au sein des études japonaises, le statut des lesbiennes, peu étudié, pose encore plus clairement la question des injonctions légales ou symboliques qui définissent la vie des femmes et des familles japonaises. Un travail de terrain et une recherche classique sur des sources essentiellement contemporaines m'ont permis de répondre à la question suivante : quelles sont aujourd'hui les attitudes des Japonaises lesbiennes concernant le mariage ? Ce mémoire détaille la réponse selon le plan suivant : après avoir énoncé le cadre de la recherche et sa méthodologie, ainsi que la situation actuelle du mariage au Japon, il s'agit de montrer dans quelle mesure les lesbiennes s'inscrivent en porte à faux par rapport au mariage hétéronormé, puis enfin de détailler les possibilités pour les Japonaises de créer une alternative à cette situation.

2 S'il reste encore très facile pour la majorité d'entre elles de se marier avec un homme, dans un souci de répondre à la norme sociale, mais aussi d'avoir une certaine sécurité économique, d'autres lesbiennes préfèrent vivre en dehors du cadre de mariage, que ce 
soit en restant célibataires ou en vivant en union libre avec leur compagne. Leur sexualité et leurs vies de couple ne sont en aucun cas reconnues officiellement : elles demeurent ainsi invisibles aux yeux de la société, comme le souligne le peu d'écho sur les minorités sexuelles dans les médias. Le mariage conditionne au Japon la délivrance d'un livret familial (koseki tōhon 戸籍謄本) : contrairement aux fiches individuelles en France, le nouvel état civil forme une entité regroupée sous un nom identique, celui du père dans $97 \%$ des cas. Ce système plutôt rigide, même s'il a été amendé depuis 1947, est toujours l'objet de critiques de la part des féministes. L'administration et la juridiction ne donnent donc aucun statut concret aux homosexuels japonais, sauf depuis 2009, dans le cas particulier du mariage d'un Japonais avec un étranger ressortissant d'un pays où les unions gaies sont reconnues. Pour ces raisons, une minorité de Japonais militent pour que les homosexuels puissent vivre en couple et fonder une famille, d'une façon légale, avec le partenariat ou avec le mariage gai. Au sein de cette communauté militante extrêmement restreinte, le groupe Pātonāhō (abréviation de Réseau national en faveur d'une loi sur le partenariat, Pātonāshippuhō zenkoku nettowāku パートナーシップ法 全国ネットワーク) fait du partenariat et du mariage gai son objet central de revendication. En outre, plusieurs Japonaises se sont regroupées à la fin des années 1990 en tant que mères lesbiennes (rezubian mazā レズビ アンマザー) pour que ce phénomène social récent soit reconnu au Japon. Étant donné que le militantisme gai et lesbien apparait à la fin des années 1970 au Japon, et que la question du mariage gai ne se pose que depuis les années 1990, un écart générationnel se dessine clairement, entre des lesbiennes qui n'avaient que le choix d'un mariage avec des hommes et celles qui peuvent envisager de vivre avec une compagne.

3 Ainsi, il y a une multitude de choix de vie et d'unions conjugales pour les lesbiennes japonaises, même si ce choix reste largement conditionné par le fait de vivre dans les grandes métropoles (Tōkyō, Ōsaka), dans les villes, à la campagne ou encore à l'étranger. Il reste plus simple de vivre en couple lesbien dans les métropoles et les grandes villes, en raisin de l'anonymat, d'une certaine liberté, mais aussi de la proximité des lieux gais et de la concentration des militants en faveur des droits des minorités sexuelles.

4 La diversité des comportements de ces femmes vis-à-vis du mariage met en évidence plusieurs éléments propres au Japon. Si l'homosexualité semble invisible dans ce pays, elle n'est pas pour autant censurée: la sexualité reste de l'ordre du privé, ce qui explique pourquoi la configuration sociale et politique des minorités sexuelles au Japon n'a rien à voir avec celle en Europe ou en Amérique. La sexualité n'est pas définie comme objet de réflexion ni de législation au Japon, elle n'est pas donnée à penser comme un élément public ou politique, d'où la difficulté supplémentaire que rencontrent les militants gais. La place des lesbiennes est particulière : contrairement aux hommes gais qui acceptent plus facilement un mariage de façade, elles commencent à contester cette possibilité, trop contraignante au niveau du rôle social que doit jouer l'épouse. De plus, les femmes peuvent plus facilement concevoir ou élever un enfant sans père, contrairement aux hommes gais, d'où la possibilité concrète de se mettre en couple lesbien. C'est pour cela que la cause du mariage gai au Japon est essentiellement portée par des femmes, qui refusent de se marier avec un homme, et qui connaissent trop bien les difficultés économiques que peut rencontrer une femme seule ou non mariée. 
Enfin, concernant la définition d'un mariage lesbien tel qu'il est revendiqué actuellement, il est remarquable de voir à quel point il se définit en regard du mariage hétérosexuel actuel. Les difficultés que rencontrent les lesbiennes à recréer leur famille ne reflètent que le poids du système matrimonial japonais. En effet, le mariage semble indispensable pour créer une famille et il reste symboliquement associé à la pratique hétérosexuelle. Il devient donc difficile de créer sa propre famille lesbienne, du moins de l'expliquer aux autres hétérosexuels, comme en témoigne l'emploi du terme « jouer à la famille»(kazoku o yatteimasu 家族をやっています) que les couples lesbiens peuvent employer. Cependant, les diverses revendications des minorités sexuelles au Japon ne font que souligner les évolutions socio-démographiques et les critiques nouvelles à l'encontre d'une structure familiale estimée trop rigide. Les années 1980 voient en effet l'apparition de plusieurs phénomènes, certes marginaux, mais qui modifient le visage de la société japonaise : les femmes veulent travailler en étant traitées à égalité avec les hommes, elles travaillent plus, l'âge moyen du mariage augmente, ainsi que l'âge moyen de la première maternité. La crise de 1990 accentue ces tendances : puisqu'entretenir une famille coûte très cher, les jeunes préfèrent vivre chez leurs parents en se mariant le plus tard possible. La famille se maintient, mais perd de sa force émotionnelle : elle garantit toujours une stabilité économique et un statut social très important. Les lesbiennes, mais aussi tous les féministes, veulent une autre politique familiale pour redéfinir le couple mère au foyer-père salarié (sengyōshufu/sarariman 専業主婦・サラリーマン), la maternité, la parentalité et le rôle des hommes dans la famille. Il y a donc aujourd'hui au Japon un espace ouvert pour réfléchir aux notions de mariage et famille, alors que la dénatalité, le vieillissement démographique et le soin aux personnes âgées ne cessent d'être définis comme les défis majeurs que va devoir relever le pays. La question de l'homosexualité féminine et du mariage s'insère dans ce cadre beaucoup plus vaste et permet de penser les contours mouvants de la norme familiale au Japon. 